\title{
Challenges Facing Globally-Minded Leaders in a Japanese-European Joint Venture Company
}

\author{
Misa Fujio \\ Faculty of Business Administration, Toyo University, Tokyo, Japan
}

Objectives: This is part of a project that investigates and clarifies the qualifications needed for globally-minded Japanese leaders, funded by a grant from the Ministry of Education, Culture, Sports, Science and Technology in Japan. This study identifies communicative problems and cultural differences that influence the performance of Japanese managers working overseas and reports the results of a focus group consisting of four Japanese expatriates working for a Japanese-European $50 \%$ joint venture company operating in a northern European country.

Methods: All the discussions of the focus group were transcribed and analyzed using the Modified Grounded Theory Approach. In an open-coding stage, nine concepts were obtained from the data, which were then categorized into three groups at the selective-coding stage: language and power, cultural awareness, and business and economic factors.

Results: In addition to the three factors presented in the selective-coding stage, the analysis indicated that there are two further obstacles facing Japanese expatriates: the occasional use of the local European language in meetings and an insufficient understanding of the local situation by the Japanese parent company.

Conclusions: The present study revealed important challenges facing Japanese expatriate staff working for a joint venture company in Europe. Although this is a study examining a Japanese-European joint venture, the results appear transferable to many other kinds of Asian and European companies.

Key Words: Language barrier, Language management, Japanese-European joint venture company, Official language vs. local language, BELF

\section{Introduction}

With an ever-increasing movement toward globalization, identifying the skill set needed for globally-minded Japanese leaders re-

Received: Oct 7, 2017 Revised: Nov 3, 2017 Accepted: Nov 19, 2017

Corresponding author: Misa Fujio

5-28-20, Hakusan, Bunkyo-ku, Tokyo 112-8606, Japan

Tel: +81-3-3945-7295, E-mail: misa.fujio@gmail.com / misa_f@toyo.jp

This is an Open Access article distributed under the terms of the Creative Commons Attribution Non-Commercial License (http://creativecommons.org/licenses/by$\mathrm{nc} / 4.0 /$ ) which permits unrestricted non-commercial use, distribution, and reproduction in any medium, provided the original work is properly cited. Copyright $\odot 2018$ Korean Association for Business Communication. mains an urgent and essential task. This study forms part of a research project funded by a grant from the Ministry of Education, Culture, Sports, Science and Technology in Japan, entitled "Strengths and challenges of Japanese globally-minded leaders from an overseas perspective". This study presents findings from a focus group consisting of four Japanese expatriates working for a Japanese-European 50\% joint venture company operating in a northern European country.

The main objectives of conducting the focus group were to first identify common communicative problems in an intercultural workplace and cultural differences that influence the business being conducted, and to then highlight ways to overcome such 
problems. Therefore, although the present study is concerned with a Japanese-European joint venture, the results are likely to be transferable to many other situations. The comments made in the focus group were analyzed using the Modified Grounded Theory Approach (Kinoshita, 2003). In the open-coding stage of that procedure, nine concepts were obtained from the data, which were then categorized into three larger groups at the selective-coding stage: one related to language, another to culture, and the final one related to business and the larger economy. The study also revealed some specific problems created by European culture, including the occasional use of the particular local European language in meetings and the difficulties in communicating details of the local situation such as different ways of decision-making back to the Japanese headquarters.

The different roles played by language in business have been discussed in various studies. Anderson and Rasmussen (2004), for example, present the following three different stances: 1) language viewed as a barrier, 2) language viewed as a facilitator, and 3) language viewed as a source of power. If we focus primarily on the accuracy of a specific language-for example, English- the English spoken by non-native speakers with a low proficiency will tend to be regarded as a barrier. On the other hand, if we consider the language spoken in terms of BELF (Business English as a Lingua Franca), then we are more likely to regard it as a facilitator (e.g., Kankarranta \& Planken 2010, Kameda 2013, Fujio 2014). The third stance, that of viewing one's language competency as a source of power, is better represented by a line of research that investigates the relationship between an employee's language ability and his/her positioning within the organization.

Feely and Harzing (2003) discuss what are called "language nodes," or employees with a good command of specific languages, who become the core of necessary professional communication, controlling in-house communication and even intentionally distorting or blocking communication from time to time in order to keep information to themselves and enhance their positioning in the organization. A similar tendency is reported by Millar and Jensen (2009). In multi-national corporations, sometimes a junior employee acquires a status s/he would not otherwise have achieved because of linguistic power. In other words, those with language skills may be overvalued in the organization.

There are also power relations among the different languages used. In most cases, English tends to gain a superordinate status, partly because it is used for official announcements. Even in Europe, where multilingualism is claimed, there is a "monolingual twist" towards English.

Another line of research relevant to the present study is concerned more directly with the communicative ability of Japanese managers working in the international arena. One of the largest studies was conducted by Yoshihara (1996) and was based on a number of different types of questionnaires. The study analyzed replies from 427 Japanese parent companies and overseas subsidiaries in an effort to investigate the processes of localization and internationalization associated with Japanese corporations as well as the degree of communicative success and remaining problems connected to English. With regard to their communication in English, several difficulties were reported, including the considerable investments of time when communicating in English, the difficulty and resulting pressure of actively speaking up in meetings, and the consequence that native speakers of English tended to dominate meetings.

Based on 61 replies to a questionnaire administered to Japanese employees working for foreign-affiliated companies operating in Japan, Fujio (2008) claims that communication problems can be categorized into four types as a result of a factor analysis: cultural differences, listening anxiety, speaking anxiety, and anxiety of unexpected problems. The last category includes the anxiety associated with non-native interlocutors with a strong accent. At the same time, however, Japanese participants reported feeling less nervous when talking with non-native speakers than with native speakers of English or in the presence of other Japanese employees who had a better command of English.

In the relevant research literature, there are also a number of studies reporting difficulties associated with taking turns in a meeting. Fujio (2012) reports that Japanese employees, even with high proficiency with TOEIC scores over 800, felt it difficult to initiate a conversation, select appropriate topics, or respond to the interlocutor appropriately (especially with humor) in English.

Tanaka (2008) analyzes turn-taking in meetings involving a French company and reports that fewer turn-taking by Japanese employees made them less powerful, claiming that not only does one's positioning in an organization influence his/her turn-taking but also that one's attitude to speaking proactively in a meeting influences his/her positioning.

All of these studies have suggested that many Japanese businesspeople working in international scenes face various kinds of language and communicative problems. In addition, taking turns smoothly in English communication could present another challenge.

In the next section, different research questions will be addressed, especially those concerning the idea of language as a source of power and the factors associated with the overall Japanese business and economic situation that influence Japanese managers working overseas. The results of the study will be presented in the form of actual comments made by the participants, along with an outline of the nine concepts obtained from the open-coding stage and their categorization at the selective-coding stage. 


\section{Methods}

\section{Background Information}

This present study examines a Japanese-European 50\% joint venture company operating in a northern European country. It seeks to identify the particular difficulties facing Japanese expatriates by means of a focus group based on particular research questions. All comments made by the focus group were transcribed and analysed using the Modified Grounded Theory Approach (Kinoshita 2003).

Although the company chosen for the study is a $50 \%$ joint venture between a Japanese and a European manufacturer, in terms of corporate structure, the selected company is a subsidiary of the European parent company. The resulting joint venture company (which will be called Company A) is involved in all of the parent company's functions including product design, product development, procurement, sales, and after-care. The main reason the Japanese company invested in and established Company A was to bring its own technology, expertise, and way of doing business into Company A. The Japanese parent company will hereafter be called Company J and the European parent company will be called Company E.

Since Company A operates in Europe, there are only 18 Japanese expatriates in a total of 900 employees, accounting for only $2 \%$ of the workforce. With regard to their system of reporting to the Japanese headquarters (Company J), there are two types of monthly reports: an official monthly report in English, which is reported to both companies (Company E and Company J), and an informal report communicated in Japanese to the Headquarters of Company J.

In northern Europe, there exists a recognized set of values regarding interpersonal interaction that is widely shared and is sometimes called The Law of Jante. That 'law' may be characterized as "a pattern of group behaviour towards individuals within Scandinavian communities that negatively portrays and criticizes individual success and achievement as unworthy and inappropriate." The behavioral tendency consists of ten rules, including "You're not to think you are anything special" or "You're not to think you are more important than we are." In this sense, the country can be regarded as sharing some common values with (the relatively high degree of) Japanese collectivism (Hofstede 1991). In fact, participants in the study discussed below talked about such similarities in values as well as the cultural differences (both will be examined in detail in the following section).

\section{Research Questions}

In order to identify the skill set needed for globally-minded Japanese leaders, the following four research questions were formed for the present study.

Research Question 1: Are there difficulties in communication between Japanese expatriates and local staff members? If so, what kind of difficulties?

Research Question 2: Are there cultural differences and similarities between Japanese expatriates and local staff members which potentially influence their business?

Research Question 3: What are the abilities and skills needed for globally-minded leaders?

Research Question 4: What should Japanese university education provide in order to foster the development of such globally-minded leaders?

\section{Participants}

Four participants were involved in the study: a financial controller, a business development manager, and two engineers. All were Japanese male expatriates in their forties and fifties. In addition, a Japanese associate professor working for a local university, who introduced the participants to the researcher, joined the focus group. However, his comments were rather occasional and excluded from the following analysis.

\section{Data Collection}

Research by means of a focus group has been regarded as a representative method for qualitative analysis in business research. The basic conditions, advantages, and disadvantages of a focus group are summarized in Morgan (1997) and Eriksson \& Kovalainen (2008). In general terms, a focus group provides better insights when conducted with a group that is relatively homogeneous in terms of age, gender, or nationality, because each participant's opinion can be more easily shared and developed among the group. From a practical point of view, the ideal number of participants is typically described as being somewhere between four and nine. If the group exceeds ten participants, there are likely to be some participants who do not find it easy to contribute.

As regards to advantages, a focus group is typically regarded as being effective for collecting a comparatively large amount of information in a limited time frame, because topics presented by a participant are likely to be developed through interaction. In such circumstances, expanded or further developed comments by other participants can provide unexpected and interesting insights. On the other hand, disadvantages associated with the method include the possibility that a few participants dominate the floor, and consequently some participants may not speak up sufficiently.

In this study, the participants in the focus group have similar backgrounds in that they received a high level of education in 
Japan, did not have extensive overseas experiences before joining this particular company, and have all worked in the same European company. Therefore, the focus group was chosen as a suitable means for data collection.

The focus group interview was conducted in November, 2015 and lasted 2 hours 27 minutes, with an intermission. As is often the case in a focus group, the author assumed the role of facilitator and asked questions based on the research questions explained above, that is, questions related to communicative problems, cultural differences and similarities that influence their business, the skill set needed for globally-minded leaders, and educational suggestions for Japanese universities. The participants were encouraged to talk freely about the topic, and the session was conducted in Japanese in order to ensure more active discussion.

\section{Method of Analysis}

All comments made during the session were transcribed and analyzed using the Modified Grounded Theory Approach (MGTA), an approach for qualitative analysis developed by Kinoshita (2003), based on the Grounded Theory Approach (GTA) pioneered by Glaser and Strauss (1967). All of the basic notions involved in the modified version are shared with GTA, including the following points.

- Data orientation: Grounded on data and leading to the formulation of concepts, categories (relationship among concepts), and a theory;

- Clear acknowledgement of the scope: Define the limitations of the data first and try to explain or predict human behaviours within that limited scope;

- Clarification of the analytical process: Analyze all the data and limit exceptions by clarifying and systematizing the analytical procedure.

The major difference between the original and modified ver- sions lies in the introduction of worksheets. M-GTA introduced worksheets for clearer and simpler analysis, instead of fragmenting the data as conducted in the GTA. Each worksheet deals with a particular concept, consisting of (1) the name of the concept, (2) the definition of that concept, (3) variations related to it (as expressed in actual comments), and (4) theoretical memos. First of all, the concept should be named carefully in order to provide a general idea of the concept at first glance. Then, the definition of the concept ( 2 above) should be carefully constructed so that the analysis related to it will not be blurred. Then, the actual comments expressed in the focus group should be sorted as they are linked to each worksheet, which represents one concept. Lastly, points noted should be written in the column of the theoretical memo (4 above) for further reference.

\section{Results}

The analytical results of the two main stages, Open Coding and Selective Coding, will be presented with actual comments made in the focus group.

\section{Open Codings}

In the first stage, Open Coding, basic concepts are formed based on actual comments. In other words, in this stage, all comments are sorted into groups, each of which forms one 'worksheet', that is, one concept. While sorting the data the researcher reaches a point of saturation or point of not being able to sort any further; this points is called "theoretical saturation" and signals the end of the analysis. Kinoshita (2003) suggests that the number of resulting concepts is likely to be about ten. In this study, the following nine concepts were formed; they are summarized in Table 1 for ease of identification, with further details presented later.

Actual comments (variations) for each concepts are present-

Table 1. Nine concepts and their definitions

\begin{tabular}{|c|c|}
\hline Concept & Definition \\
\hline Language ability as a barrier & How linguistic inability becomes a barrier \\
\hline Differences in the way of working/employment system & How working style and the employment system differ between this county and Japan \\
\hline Differences in the way of decision-making & How ways of making decisions differ between this county and Japan \\
\hline Cultural similarities between the two countries & How similar the two countries are in cultural values, despite other differences \\
\hline Education to encourage speaking up & $\begin{array}{l}\text { Why and how education to facilitate speaking up is necessary for globally-minded Japa- } \\
\text { nese leaders }\end{array}$ \\
\hline Training to enhance intercultural competence & $\begin{array}{l}\text { Why and how education to enhance cultural awareness is needed for globally-minded } \\
\text { Japanese leaders }\end{array}$ \\
\hline Reduced Japanese presence or influence & Why and how the presence and influence of Japan has been declining overseas \\
\hline Underdeveloped globalization of Japanese companies & Why and how Japanese corporations are underdeveloped in terms of globalization \\
\hline Caution in overemphasizing "globalization" & Why and how the term globalization is overemphasized, without enough discussion \\
\hline
\end{tabular}


Table 2. Nine concepts and their representative comments

\begin{tabular}{|c|c|}
\hline Concept & Representative comments \\
\hline $\begin{array}{l}\text { Language ability } \\
\text { as a barrier }\end{array}$ & $\begin{array}{l}\text { - Here, I have to make extra efforts to reach the same output as I did in Japan, due to my English ability. } \\
\text { - Here, those who speak more tend to be regarded as those who work harder. The dominant opinions in a meeting tend to be } \\
\text { adopted. In this sense, speaking up itself is nearly equal to power. } \\
\text { - In my section, I'm the only Japanese participant. So, sometimes the other employees use the local language, not even English. }\end{array}$ \\
\hline $\begin{array}{l}\text { Differences in the } \\
\text { way of working/ } \\
\text { employment } \\
\text { system }\end{array}$ & $\begin{array}{l}\text { - In Japan, before presenting our ideas [about product design] to others, we need a lot of approval. But here, the ideas of the } \\
\text { person in charge are more easily implemented. } \\
\text { - Job description and role assignment are very clear. Unlike Japanese, people here don't work outside their job description or } \\
\text { the gray zone. }\end{array}$ \\
\hline $\begin{array}{l}\text { Differences in the } \\
\text { way of deci- } \\
\text { sion-making }\end{array}$ & $\begin{array}{l}\text { - Decision-making is very speedy. It's called the sand box system just like children's playing in a sand box. Just three or four } \\
\text { people get together, brainstorm, and start to work, using the budget freely. It takes only } 2 \text { years here to make a product that } \\
\text { takes } 5 \text { to } 6 \text { years in Japan. } \\
\text { - Japanese companies tend to discuss thoroughly, taking a lot of time. Here, people make a decision in a fixed time, just in a } \\
\text { meeting. }\end{array}$ \\
\hline $\begin{array}{l}\text { Cultural similari- } \\
\text { ties between the } \\
\text { two countries }\end{array}$ & $\begin{array}{l}\text { - A nail that stands will be hammered down. (The Law of Jante) } \\
\text { - People here like socializing among colleagues even more than the Japanese. } \\
\text { - They prefer face-to-face communication rather than e-mails. }\end{array}$ \\
\hline $\begin{array}{l}\text { Education to en- } \\
\text { courage speak- } \\
\text { ing up }\end{array}$ & $\begin{array}{l}\text { - In order to foster globally-minded leaders, speaking English and the ability to express one's opinions should be taught at an } \\
\text { early stage, such as elementary school. } \\
\text { - The communication ability in Japanese should be developed first. High TOEIC scores do not guarantee speaking ability. In- } \\
\text { stead, the ability to speak up should be taught. }\end{array}$ \\
\hline $\begin{array}{l}\text { Training to en- } \\
\text { hance intercul- } \\
\text { tural compe- } \\
\text { tence }\end{array}$ & $\begin{array}{l}\text { - Both Japan and this country are homogeneous societies and cannot accept diversity. In the Netherlands, the leader listens to } \\
\text { everybody's opinions, skillfully accepting different opinions to reach a consensus. } \\
\text { - First of all, we have to get younger generations interested in foreign countries. They should go abroad to study like Chinese } \\
\text { and Korean students. }\end{array}$ \\
\hline $\begin{array}{l}\text { Reduced Japanese } \\
\text { presence or in- } \\
\text { fluence }\end{array}$ & $\begin{array}{l}\text {-The presence of Japan has sharply decreased. Here, we cannot even find guidebooks for Japan. There used to be Japanese TV } \\
\text { programs, but now they have been replaced with Chinese programmes. Now everything has become China-oriented. } \\
\text { - For globalization, we should think about how to raise the presence of Japan. } \\
\text { - The impact of globally-minded leaders varies from economy to culture. So, appealing to cultural strengths is one way to raise } \\
\text { the presence of Japan. }\end{array}$ \\
\hline $\begin{array}{l}\text { Underdeveloped } \\
\text { globalization of } \\
\text { Japanese com- } \\
\text { panies }\end{array}$ & $\begin{array}{l}\text {-The Japanese headquarters doesn't necessarily understand the way of doing business in Europe. They want to know every- } \\
\text { thing. But we cannot comprehend the big picture because here, projects are based on individuals and not shared by every- } \\
\text { one like they are in Japan. } \\
\text { - Japan has been very technology-oriented. But the world standard has been controlled by Western countries, [That's why we } \\
\text { could not be dominant in some markets]. One good example is the mobile market. Unless we think about how to control the } \\
\text { world-wide standard, we'll never be No.1, however good our technology is. }\end{array}$ \\
\hline $\begin{array}{l}\text { Caution for over- } \\
\text { emphasizing } \\
\text { "Globalization" }\end{array}$ & $\begin{array}{l}\text { - Now, the term globalization is widely used, but its implications are not understood. } \\
\text {-We can just imitate Western countries if we really wish. But we should think about Japan's strengths and unique selling points } \\
\text { to appeal to the world. } \\
\text { - Even though we successfully train globally-minded leaders, what would happen if they stayed abroad forever? We should } \\
\text { think about how they can return their fruits to the Japanese society. }\end{array}$ \\
\hline
\end{tabular}

ed in Table 2, although only two or three are given by way of illustration because of space limitations. The comments were translated by the author from Japanese into English. For comments that may be somewhat difficult to understand without the relevant context, the author has added brackets. 'Here' in the comments refers to the situation in the given country.

\section{Selective Coding}

In the next stage of the research process, the Selective Coding stage, the concepts formulated during the open coding stage are categorized into larger, consolidated groups, connecting closely related concepts together. In this study, the author categorized them into three larger groups: language and power (language level), cultural awareness (cultural level), and business and economic factors (economic level). Each group can be seen as consisting of two axes: factors influencing business and challenges related to more successful communication (Figure 1).

Figure 1 indicates the problems globally-minded Japanese 


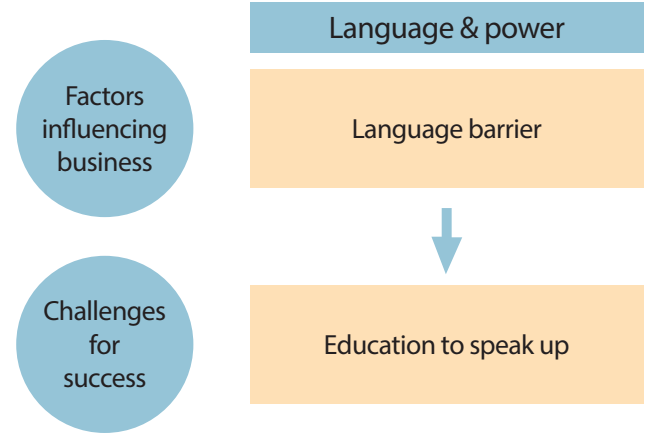

Figure 1. Categorization of the nine concepts.

leaders need to consider simultaneously at three levels: language, culture, and economy. In general terms, problems at the economic level are beyond the ability to change for any individual or corporation, though some countermeasures could be taken at the national level. On the other hand, problems at the language and cultural levels could be resolved to some extent through individual efforts.

\section{Discussion}

In this section, a response will be given to each of the research questions stated above, as well as a discussion of topics highlighted in the previous section: language and power; and business and economic factors influencing Japanese businesspeople working overseas.

\section{Communication Diffficulties (Question 1)}

In this study, both linguistic and cultural problems were confirmed by the focus group, as presented in the previous section. Here, an important topic mentioned by all the participants will be highlighted: that is, language and power.

The point was made on more than one occasion that the ability to speak up in a meeting significantly shapes the power relationships in play, because in this European country, many agenda items are immediately decided during the meeting, unlike in Japan, where decision-making requires a great deal of time, as it often includes Ringi (a typical Japanese procedure in which a written document is circulated among managers to receive approval from each manager). Therefore, the ability to speak up in a meeting can directly influence decision-making, and it consequently contributes to determining one's relative positioningrather than formal position-in an organization.

This finding supports a finding of the study by Tanaka (2008), and it is likely that this tendency can be observed clearly in Company A because it operates in Europe as a joint venture. In this case, neither the mother tongue of Company E's employees nor
Company J's is English. They all have equal standing in being non-native speakers and employees of the same joint venture company, but with varying degrees of English ability, such that the varying English ability might directly influence one's possible turn-taking. In further research, it would be interesting to compare the results of the present study with the different cases of different organizations or different locations, for example, the case of a Japanese subsidiary operating overseas, in which Japanese expatriates would be typically likely to exercise more power (e.g., Fujio, 2016).

The present research suggests that communication problems are not limited to internal communication in English, however. One of the participants in the focus group commented that sometimes the local language is used in meetings because all the other participants in his department are local people. A similar finding can be found in Harzing and Feely (2008), where it is described in the following way:

Code switching is present when second language users, generally at key moments in a meeting, huddle together and revert to talking between themselves in their native language. It is easy to understand the need; however, to the out-group members, who probably do not speak the other group's language, such a switching of codes "just when it was getting interesting" smacks of conspiracy and double-dealing (p.55).

The complex conventions governing interaction outlined here imply another obstacle facing Japanese expatriates, that is, possessing a good command of the local language in order to understand the local employees.

In addition, some participants in the focus group reported that staff at the Japanese Headquarters do not necessarily understand what has been going on in the local office or local culture, including how the decision-making takes place (Table 2). As a result, reporting the current situation to headquarters can become another significant issue for Japanese staff working 
overseas. The difficulty appears to be a long-standing and possibly deep-seated challenge, since a very similar problem was reported by Yoshihara as far back as 1996, yet remains a major challenge for the future in Japanese corporations.

\section{Cultural Differences and Similarities (Question 2)}

All participants mentioned cultural differences in the way of decision-making and in working style (Table 2). They observed that each employee has greater decision-making authority and the budget to implement decisions in Company $\mathrm{A}$, as compared to Company J. Although such an arrangement speeds up business, it causes another problem that each employee tends to work on his/her own job but is less likely to grasp the overall, bigger picture, including the progress being made by other individuals. As shown in Table 2, since the Japanese Headquarters wishes to understand everything happening in the local office, such information and reporting gaps sometimes trouble Japanese expatriates, who are not necessarily informed of other employees' progress.

With regard to cultural factors, comments by all participants were made not only about differences but also about cultural similarities. Such comments reflect the tendency described above as the Law of Jante. This might imply that in an intercultural business arena, we may pay more attention to cultural similarities, which establish rapport with the interlocutor, rather than being attentive to cultural differences, which focus on differences or discrepancies between parties.

\section{Educating Globally-Minded Leaders (Questions 3 \& 4)}

The last two research questions are discussed together because the answers to overlap on many points: What are the abilities and skills needed for globally-minded leaders and what should Japanese university education provide in order to foster the development of such globally-minded leaders.

Among the concepts listed in Table 1, both "Education to encourage speaking up" and "Training to enhance intercultural competence" are concerned with these questions. In particular, specific comments such as "In order to foster globally-minded leaders, speaking English and how to express one's opinions should be taught at an early stage" and "Both Japan and this country are homogeneous societies and cannot accept diversity" indicate that informants in the focus group have paid particular attention to intercultural communicative competence or intercultural competency (e.g. Byram 1997, Spencer-Oatey \& Stadler 2009).

Among various models of intercultural competency, that of Spencer-Oatey and Stadler (2009) will be especially helpful for those working in an international arena, in that they include a relational aspect (rapport building) as well as a strategic aspect (communication management) in their model (which consists of "knowledge", "communication", "relationships" and "personal qualities and dispositions"). Communication management in this model includes not only language adjustment attuned to the interlocutor's language ability but also the choice of communication mode (such as e-mail or face-to-face communication) and the establishment of a suitable communication network (including the appropriate choice of the person to speak to).

In the present study, the importance of communication management is reaffirmed in the context of difficulties in speaking up or taking turns smoothly and in a timely manner in meetings. This indicates that the relatively lower language ability of Japanese businesspeople and their hesitation to take turns are likely to make them less strategic speakers in English communication, an observation that supports Fujio's proposal (2012) that English education in Japan should incorporate practical work on how to manage conversation, including turn-taking, rather than just focusing on language accuracy.

In these and other ways, the results of this study confirm that the challenges facing globally-minded Japanese leaders will need to be resolved at all three of the levels distinguished in this and earlier related studies: individual, corporate, and national (cf. Adachi 2000, Norisada 2005). In this study in particular, comments concerned with the world standard or reduced presence of Japan in the global business environment suggest that we should be more strategic in seeking to regain power in the world economy in ways likely to influence the success of individual Japanese managers working overseas.

\section{Conclusion}

The research reported above has presented findings from a focus group consisting of four Japanese expatriate staff working for a Japanese-European joint venture company operating in Europe. It has revealed important challenges facing such staff at the linguistic, cultural, and economic levels. Although the findings come from a specific case study and have consequent limitations in respect to size and representativeness, the richness of the descriptions made possible by the focus group format allows some transferability to other situations, especially as regards to language management in corporations operating internationally, using English for official purposes and the local language for informal communication. Comparison between the present study and related situations, such as cases of Japanese corporations operating overseas or joint venture companies in different locations, may lead to further insights regarding the relationship between language management and corporate structure. When 
viewed in the larger context in which an increasing number of Japanese corporations have started using English as an official language, either partially or totally, empirical studies investigating questions of the kind addressed in this study will be urgently needed.

\section{Acknowledgements}

The current study is part of a research project supported by JSPS KAKENHI Grant Number JP15K02764. I am also indebted to the research participants, who provided me with valuable comments, and to Professor Alan Durant and the BCRP editorial board of this journal for their careful proofreading and editing.

\section{References}

Adachi, Y. (2000). The importance of communication ability as a national asset. Management Communication Review, 1, 3-28.

Anderson, H., \& Rasmussen, E. S. (2004). The role of language skills in corporate communication. Corporate Communications, 9(3), 231-242.

Byram, M. (1997). Teaching and assisseing intercultural communicative competence. UK: Multilingual Matters.

Eriksson, P., \& Kovalainen, A. (2008). Qualitative methods in business research. London, UK: SAGE.

Feely, A. J., \& Harzing, A. (2003). Language management in multinational companies. Cross-Cultural Management: An International Journal, 10(2), 37-52.

Fujio, M. (2008). Positive and negative effects of English communication in foreign-affiliated companies operating in Japan. Journal of International Business Communication Association, 67, 61-72.

Fujio, M. (2012). Needs analysis of Japanese employees working for foreign-affiliated companies - Suggestions for future ESP education. In the Professor Paul Rossiter Festschrift Editorial Committee (Ed.), West to East, East to West (pp. 175-207). Tokyo, Japan: Seibido.

Fujio, M. (2014). New opportunities BELF can create for Japanese business people in intercultural business scenes: How can we be- come successful "native-speakers" of BELF? Doshisha Shougaku, 65(5), 95-111.

Fujio, M. (2016). The strengths and weaknesses of Japanese globally-minded leaders: A case study of a Japnaese manufacturer. Journal of International Business Communication Association, 75, 3-12.

Glaser, B., \& Strauss, A. L. (1967). The discovery of grounded theory: Strategies for qualitative research. New York, NY: Aldine.

Kameda, N. (2013). Future prospects of BELF: Diversion or conversion. The Doshisha Business Review, 64(6), 1213-1227.

Kankaanranta, A., \& Planken, B. (2010). BELF competence as business knowledge of internationally operating business professionals. Journal of Business Communication, 47(4), 381-407.

Kinoshita, Y. (2003). Modified Grounded Theory Approach. Tokyo, Japan: Kobundo.

Harzing, A., \& Feeley, A. J. (2008). The language barrier and its implications for HQ-subsidiary relationships. Cross-Cultural Management, 15(1), 49-61.

Hofstede, G. (1991). Cultures and organizations: Software of the mind. London, UK: Collins Business.

Millar, S. L., \& Jensen, A. (2009). Language choice and management in Danish multinational companies: The role of common sense. Sociolinguistica: Internationales Jahrbuch Fuer Europaeische Soziolinguistik, 23, 86-103.

Morgan, D. L. (1997). Focus groups as qualitative research. Thousands Oaks, CA: Sage.

Norisada, T. (2005). Linguistic ability as a competitive advantage: Three dimensions of an individual, a company, and a nation. Journal of International Business Communication Association, 65, 2333 .

Spencer-Oatey, H., \& Stadler, S. (2009). The global people competency framework. Warwick Occasional Papers in Applied Linguistics, 3, 1-36.

Tanaka, H. (2008). Communication strategies and cultural assumptions: An analysis of French-Japanese business meetings. In S. Tietze (Ed.), International management and language (pp. 154170). New York, NY: Routledge.

Yoshihara, H. (1996). Immagure international management. Tokyo, Japan: Hakuto Shobo. 